\title{
Minichromosome maintenance protein 2 and 3 promote osteosarcoma progression via DHX9 and predict poor patient prognosis
}

\author{
Dong-dong Cheng ${ }^{1, *}$, Hui-zhen Zhang ${ }^{2, *}$, Jun-qing Yuan ${ }^{2, *}$, Shi-jie Li ${ }^{1}$, Qing-cheng \\ Yang ${ }^{1}$, Cun-yi Fan ${ }^{1}$ \\ ${ }^{1}$ Department of Orthopedics, Shanghai Jiao Tong University Affiliated Sixth People's Hospital, Shanghai, 200233, China \\ ${ }^{2}$ Department of Pathology, Shanghai Jiao Tong University Affiliated Sixth People's Hospital, Shanghai, 200233, China \\ *Authors share co-first authorship
}

Correspondence to: Cun-yi Fan, email: fancunyi888@hotmail.com Qing-cheng Yang, email: tjyqc@163.com

Keywords: MCM2, MCM3, DHX9, proliferation, osteosarcoma

Received: November 14, $2016 \quad$ Accepted: February 07, $2017 \quad$ Published: February 18, 2017

Copyright: Cheng et al. This is an open-access article distributed under the terms of the Creative Commons Attribution License (CC-BY), which permits unrestricted use, distribution, and reproduction in any medium, provided the original author and source are credited.

\section{ABSTRACT}

A label free quantitative proteomic approach (SWATH ${ }^{\mathrm{TM}}$ experiment) was performed to identify tumor-associated nuclear proteins that are differentially expressed between osteosarcoma cells and osteoblast cells. By functional screening, minichromosome maintenance protein 2 (MCM2) and minichromosome maintenance protein 3 (MCM3) were found to be related to osteosarcoma cell growth. Here, we show that knockdown of MCM2 or MCM3 inhibits osteosarcoma growth in vitro and in vivo. In co-immunoprecipitation and co-localization experiments, MCM2 and MCM3 were found to interact with DExH-box helicase 9 (DHX9) in osteosarcoma cells. A rescue study showed that the decreased growth of osteosarcoma cells by MCM2 or MCM3 knockdown was reversed by DHX9 overexpression, indicating that MCM2 and MCM3 activity was DHX9-dependent. In addition, the depletion of DHX9 hindered osteosarcoma cell proliferation. Notably, MCM2 and MCM3 expression levels were positively correlated with the DHX9 expression level in tumor samples and were associated with a poor prognosis in patients with osteosarcoma. Taken together, these results suggest that the MCM2/MCM3-DHX9 axis has an important role in osteosarcoma progression.

\section{INTRODUCTION}

Osteosarcoma, a malignant tumor of mesenchymal origin, is the most common primary bone sarcoma in children and adolescents [1]. Improvements in surgical treatment and the development of new chemotherapy drugs have significantly decreased the number of amputations. Over time, patient survival has improved from less than $30 \%$ to greater than $70 \%$ [2]. Despite these advances, the survival rates for osteosarcoma have reached a plateau [3]. Nowadays, many patients remain insensitive to chemotherapy and have a poor prognosis. Therefore, there is still an urgent need to investigate novel chemotherapeutic targets.

Accumulating evidence indicates that nuclear proteins, located in the nuclei of cells, play important roles in the genesis and progression of various cancers. Shahbazi et al. [4] reported that the repression of the nuclear protein TP53INP1 is an important co-factor for N-Myc oncogenesis, suggesting a new therapeutic approach for N-Myc-induced neuroblastoma. MTHFD2, a nuclear protein, co-localizes with DNA replication sites and sufficiently promotes cancer cell proliferation [5]. Pedrola et al. reported that Nuclear Protein 1 (NUPR1) was a direct target of the transcription factor ETV5 in endometrial cancer; the inhibition of NUPR1 reduced cell migration and invasion in vitro and reduced tumor growth and dissemination in an orthotopic endometrial cancer model [6]. Mass spectrometry-based proteomics is a powerful tool for biological and clinical research and enables relatively comprehensive global analyses $[7,8]$. Relative quantitation with stable isotope labeling 
or label-free methods is widely used to study differential protein expression profiles [9-11]. $\mathrm{SWATH}^{\mathrm{TM}}$ is a recently developed label-free quantitative proteomic approach based on a data-independent acquisition (DIA) strategy and it can successfully quantify compounds with high complexity $[12,13]$. The systematic analysis of the expression levels of nuclear proteins using SWATH ${ }^{\mathrm{TM}}$ provides an effective approach to identify molecules involved in carcinogenesis.

In the present study, a SWATH ${ }^{\mathrm{TM}}$ analysis was performed using osteosarcoma cell lines (MNNG/HOS and U2OS) and an osteoblast cell line (hFOB 1.19). By functional screening, MCM2 and MCM3, components of the MCM2-7 complex, were found to be related to osteosarcoma proliferation. Several studies have demonstrated that MCM proteins can be used as proliferation markers to predict the behaviors of diverse tumors $[14,15]$. However, the functions and molecular mechanisms of MCM2 and MCM3 in osteosarcoma are still far from fully understood. The results of this study demonstrated that knockdown of MCM2 or MCM3 inhibited osteosarcoma cell growth in vitro and in vivo. MCM2 and MCM3 were found to interact and co-localize with DHX9 in osteosarcoma. Overexpression of DHX9 could rescue MCM2 or MCM3 knockdown-induced tumor inhibition. Further analyses showed that the inhibition of DHX9 hindered osteosarcoma cell proliferation. Notably, we found that MCM2 and MCM3 were independent prognostic factors for tumor-free survival (TFS) and overall survival (OS) in patients with osteosarcoma. A positive correlation between $\mathrm{MCM} 2$ or $\mathrm{MCM} 3$ and DHX9 expression was detected in osteosarcoma tissues. Taken together, MCM2 and MCM3 promote osteosarcoma progression via associations with DHX9 and thus are potential therapeutic targets for patients with osteosarcoma.

\section{RESULTS}

\section{Comparative nuclear proteome profile of osteoblast cells versus osteosarcoma cells}

In the present study, SWATH ${ }^{\mathrm{TM}}$ measurement was used to determine differentially expressed nuclear proteins between osteoblast cells (hFOB 1.19) and osteosarcoma cells (MNNG/HOS and U2OS). The flowchart of the proteomic analysis is shown in Figure 1A. In the SWATH ${ }^{\mathrm{TM}}$ experiments, a total of 1549 proteins (global FDR $<1 \%$ ) were identified. To ensure confident quantitative results, we selected the proteins with at least 2 peptides identified using PeakView ${ }^{\circledR}$ for subsequent analyses. Using this filter, 1254 proteins were quantified repeatedly in four technical replicates (Figure 1B). In total, 62 upregulated proteins and 87 downregulated proteins were identified in all osteosarcoma cell lines compared to the osteoblast cell line (Figure 1C). A heatmap of deregulated proteins in osteosarcoma cells is shown in Figure 1D. Gene ontology (GO) and Kyoto Encyclopedia of Genes and Genomes (KEGG) pathway analyses [16] were performed to evaluate the differentially expressed proteins (Supplementary Figure 1). 18 upregulated proteins and 5 downregulated proteins were selected to further validate the proteomic results. The mRNA expression levels of these proteins, as determined by qRT-PCR, were consistent with the results of the proteomic analysis (Figure 1E and 1F). Then, 11 upregulated proteins, i.e., Rb, MCM2, GTF3C4, MCM3, PKM, IMPDH2, CTBP1, ANP32A, FHL1, NME1, and NME2, and one downregulated protein, CSRP1, were chosen to verify the results at the protein level. The expression levels of these proteins were consistent with the results of the proteomic analysis (Figure 1G). These results collectively support the feasibility of our approach for identifying osteosarcoma-associated nuclear proteins.

\section{Functional screening osteosarcoma proliferation- related nuclear proteins}

To determine osteosarcoma proliferation-related nuclear proteins, functional screening by siRNA knockdown and CCK-8 assay [17] were performed. We chose 9 nuclear proteins, namely, MCM2, GTF3C4, MCM3, PKM, CTBP1, ANP32A, FHL1, NME1, and NME2, which might be associated with osteosarcoma oncogenesis. The results showed that the inhibition of MCM2 or MCM3 could restrain the proliferation of osteosarcoma cells, whereas the inhibition the other proteins had no effect on the proliferation of osteosarcoma cells (Figure 2). In sum, we hypothesized that MCM2 and MCM3 were associated with the proliferation of osteosarcoma cells.

\section{The role of MCM2 and MCM3 in osteosarcoma cells in vitro}

To explore the functional significance of MCM2 and MCM3 in osteosarcoma, MCM2-specific or MCM3specific siRNA was used to knockdown MCM2 or MCM3 in two osteosarcoma cell lines, MNNG/HOS and U2OS. MCM2 or MCM3 knockdown was validated by qRTPCR and western blot analyses. The mRNA and protein expression levels of MCM2 and MCM3 were significantly reduced after transfection with siRNA in MNNG/ HOS and U2OS cells (Figure 3A-3H). A CCK-8 assay was used to detect cell proliferation. The data revealed that the knockdown of MCM2 or MCM3 significantly inhibited the growth of osteosarcoma cells (Figure 3I-3L). Similarly, a colony formation assay showed that the knockdown of MCM2 or MCM3 attenuated the formation of cell colonies (Figure 3M-3P). These results suggest that the overexpression of MCM2 or MCM3 has an oncogenic role in osteosarcoma. 


\section{Knockdown of MCM2 or MCM3 inhibits tumor growth in vivo}

To further determine the effects of MCM2 and MCM3 on osteosarcoma growth in vivo, MNNG/HOS cells stably expressing sh-control, sh-MCM2, and sh-MCM3 were constructed. Protein expression was validated by western blotting (Figure 4A). Then, cells were subcutaneously injected into the left scapulas of nude mice, and the animals were closely monitored for tumor growth for 6 weeks. The tumor growth curve demonstrated that the knockdown of MCM2 or MCM3 significantly inhibited tumor growth in vivo. The tumor volume and weight were smaller in the MCM2 and MCM3 knockdown groups than the scramble group (Figure 4B-4D). As shown in Figure $4 \mathrm{E}$ and $4 \mathrm{~F}$, based on an immunohistochemical analysis, the levels of the tissue proliferation marker Ki-67 [18] was lower in the sh-MCM2 and sh-MCM3 tumors compared to those in sh-control tumors. Taken together, these results indicated that MCM2 or MCM3 knockdown could hinder the tumorigenesis of osteosarcoma cells in vivo.

\section{MCM2 and MCM3 interact with DHX9 in osteosarcoma cells}

In order to determine the underlying mechanism by which MCM2 and MCM3 promote osteosarcoma, coimmunoprecipitation was performed in $293 \mathrm{~T}$ cells. After protein identification by mass spectrometry, 6 proteins (DHX9, DDX21, RPL4, FBL, RPL7, and RPL7A) were chosen for further verification (Figure 5A). To assess interactions between proteins, we pulled down MCM2 or MCM3 and probed their interactions with other proteins in $293 \mathrm{~T}$ cells and osteosarcoma cells. We found that
A

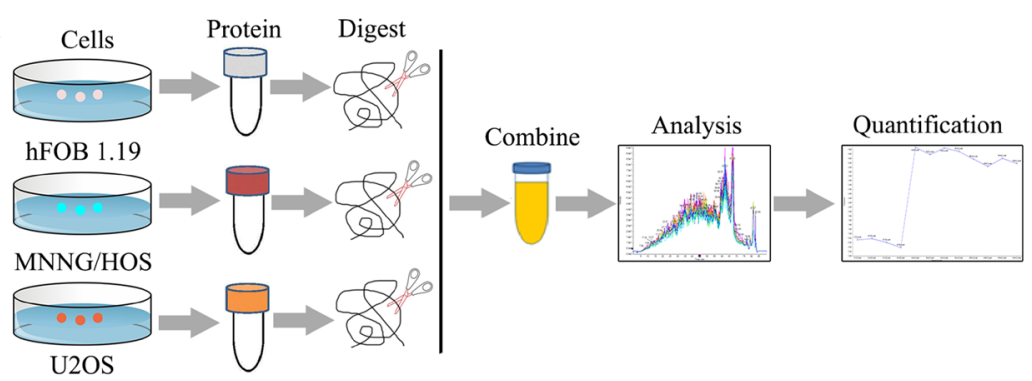

B

The number of identified and quantified proteins (unused protein score $>1.3$ and peptides $>=2$ )

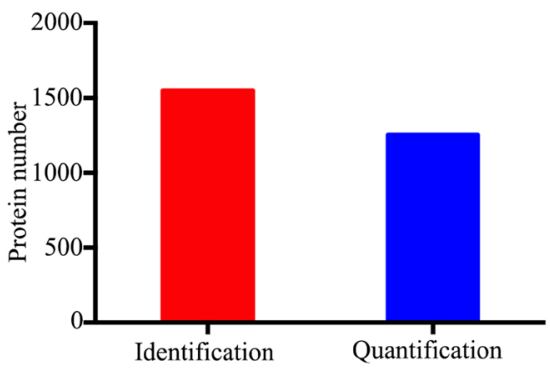

C

The number of over expressed and low expressed nuclear proteins in osteosarcoma

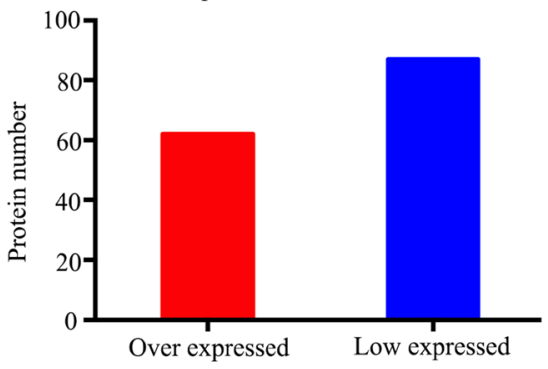

$\mathrm{D}$

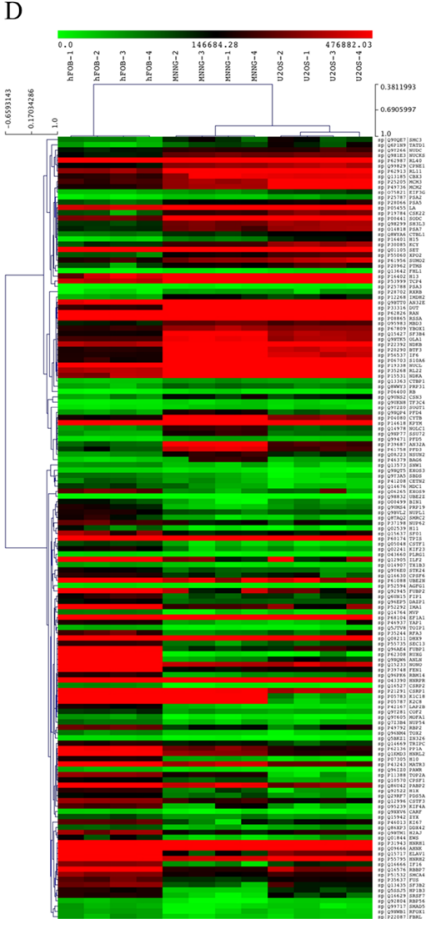

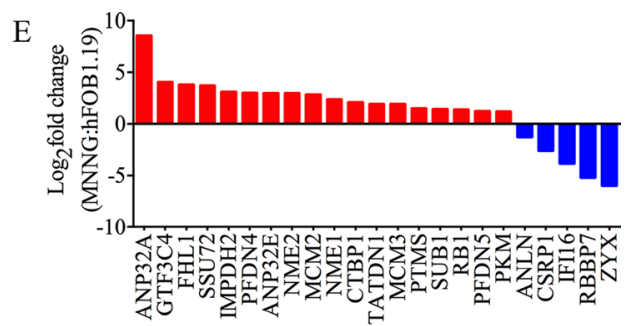

$\mathrm{F}$

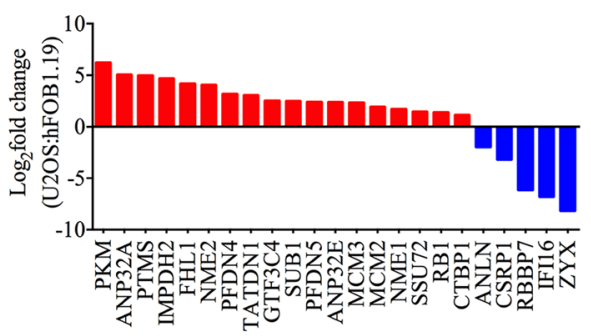

G

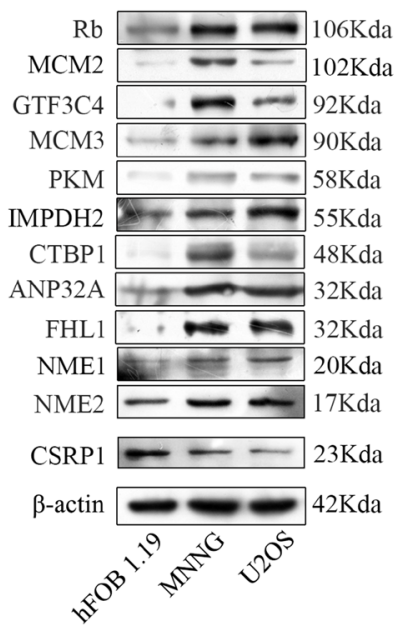

Figure 1: Experimental workflow for the SWATH ${ }^{\mathrm{TM}}$ quantitative proteomics analysis. (A) Flowchart of the proteomic analysis. (B) Numbers of identified and quantified nuclear proteins in the SWATH ${ }^{\mathrm{TM}}$ analysis. (C) Numbers of upregulated and downregulated nuclear proteins in osteosarcoma cells. (D) A heat map of dysregulated proteins in osteosarcoma. (E, F) The mRNA expression levels of 18 upregulated and 5 downregulated nuclear proteins in MNNG/HOS and U2OS cells compared with hFOB 1.19 cells were verified by qRT-PCR. (G) Representative blots display the protein expression levels of 11 upregulated and one downregulated nuclear proteins. $\beta$-actin was used as an internal control. 
MCM2 and MCM3 specifically interacted with DHX9, as indicated by an immunoprecipitation assay (Figure 5B), whereas no interactions were observed with other proteins (Supplementary Figure 2). No interaction was found between MCM2 and MCM3 in osteosarcoma cells. In addition, DHX9 interacted with MCM2 and MCM3 in MNNG/HOS cells (Figure 5C). We also confirmed the co-localization of MCM2 and MCM3 with DHX9 in MNNG/HOS cells by confocal microscopy (Figure 5D). Thus, MCM2 and MCM3 are associated with DHX9 in osteosarcoma cells.

\section{Knockdown of MCM2 or MCM3 inhibits osteosarcoma cell proliferation via DHX9}

Our data demonstrated that knockdown of MCM2 or MCM3 inhibited osteosarcoma cell proliferation. However, the role of DHX9 in osteosarcoma and whether MCM2 and MCM3 function via DHX9 are largely unknown. Since MMC2 and MCM3 interact with DHX9 in osteosarcoma cells, it is plausible that they function via DHX9, and DHX9 plays an important role in osteosarcoma cell proliferation. We overexpressed DHX9 in MCM2 or MCM3 knockdown MNNG/HOS and U2OS cells. As expected, DHX9 overexpression rescued the MCM2 or MCM3 knockdown-induced cell growth inhibition (Figure 6A-6D). Then, DHX9-specific siRNA was used to knockdown DHX9 in osteosarcoma cells. DHX9 knockdown was validated by qRT-PCR and western blotting (Figure 6E and 6G). A CCK-8 assay and colony formation assay were used to detect cell proliferation. These data revealed that the knockdown of DHX9 significantly inhibited the growth of osteosarcoma cells (Figure 6F, 6H, and 6I-6L). Collectively, these results reveal that knockdown of MCM2 or MCM3 inhibits osteosarcoma cell proliferation via DHX9 and DHX9 plays an oncogenic role in osteosarcoma.

\section{High expression of MCM2 and MCM3 is significantly associated with worse prognosis in osteosarcoma}

To further determine the clinicopathological significance of MCM2 and MCM3 in osteosarcoma, we performed an immunohistochemical (IHC) analysis of MCM2 and MCM3 using a tissue microarray that included an independent set of 129 cases of osteosarcoma. Representative images of MCM2 and MCM3 expression results are shown in Figure 7A and 7B. The correlations between MCM2, MCM3 expression levels and the clinicopathological characteristics of osteosarcoma patients are summarized in Table 1. The expression levels of MCM2 and MCM3 were higher in patients with clinically advanced Enneking stage than those at an early stage $(P=0.000)$. Further analysis indicated that MCM2 and MCM3 levels were positively correlated with recurrence $(P=0.000)$, indicating that MCM2 and MCM3 play important roles in osteosarcoma recurrence. A univariate analysis showed that TFS was related to MCM2 $(P=0.000), \operatorname{MCM} 3(P=0.000)$, and Enneking stage $(P=0.000)$ (Table 2$)$. OS was related to MCM2 $(P=0.000), \operatorname{MCM} 3(P=0.000)$, and Enneking stage $(P=0.000)$ (Table 2). Variables that exhibited significant differences in a univariate analysis were included in a multivariate analysis. A multivariate Cox regression analysis showed that MCM2 $\left(\chi^{2}=4.333, \mathrm{HR}=1.603\right.$,

A

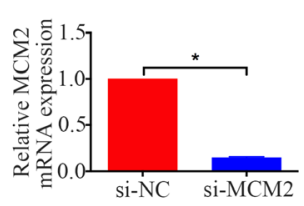

MCM2

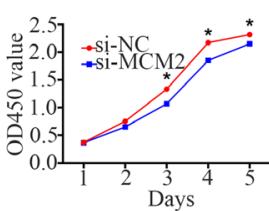

$\mathrm{D}$
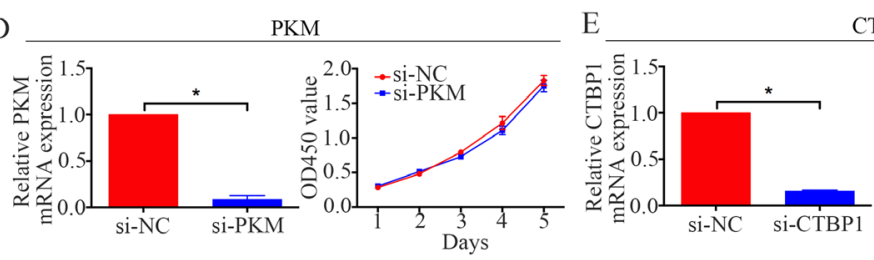

GTF3C4
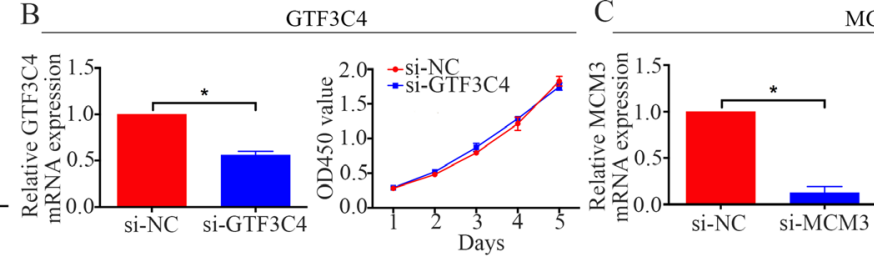

MCM3
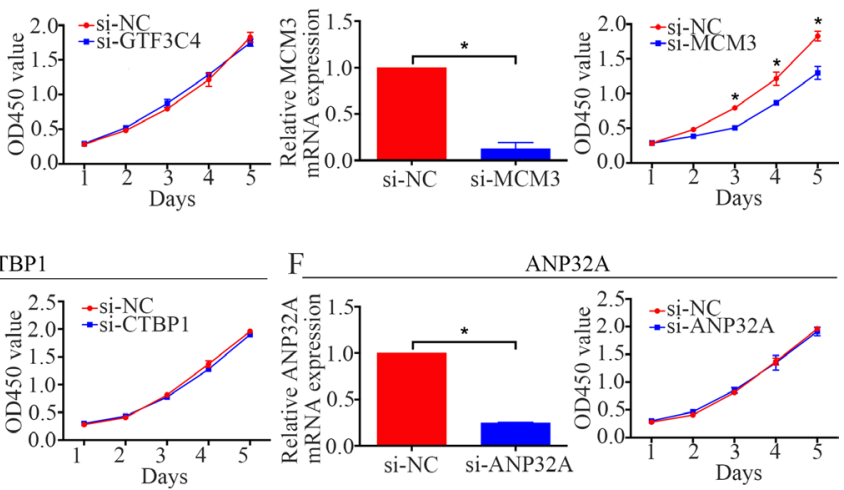

G
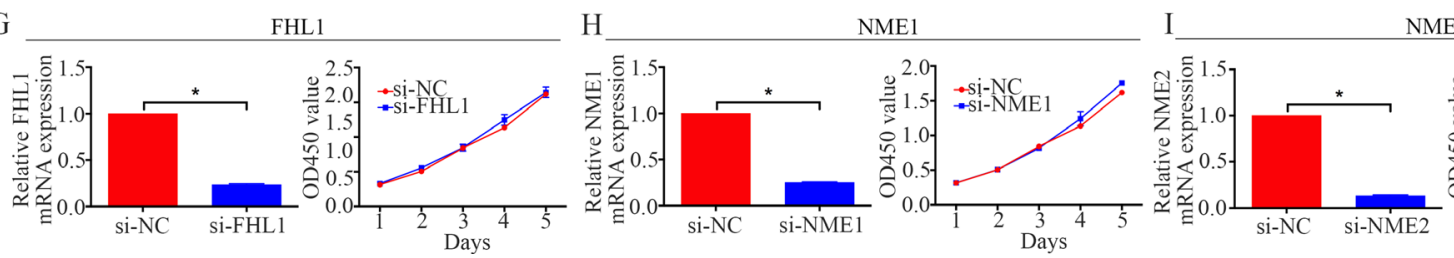

NME2

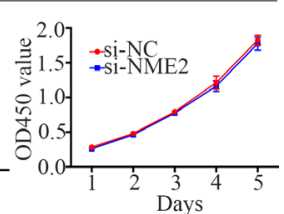

Figure 2: Functional screening of 9 candidate nuclear proteins in the MNNG/HOS cell line. A CCK-8 assay was used to detect the proliferation of $\mathrm{MNNG} / \mathrm{HOS}$ cells after transfection with siRNA. $* P<0.05$. 
Table 1: MCM2 and MCM3 expression status $n$ (\%)

\begin{tabular}{|c|c|c|c|c|c|c|c|c|c|c|}
\hline \multirow{2}{*}{$\begin{array}{c}\text { Clinicopathologic } \\
\text { parameters }\end{array}$} & \multicolumn{4}{|c|}{ MCM2 expression level } & \multirow{2}{*}{$p$ value } & \multicolumn{4}{|c|}{ MCM3 expression level } & \multirow{2}{*}{$p$ value } \\
\hline & Negative & Low & Middle & Strong & & Negative & Low & Middle & Strong & \\
\hline Gender & & & & & 0.983 & & & & & 0.708 \\
\hline Male & 24 & 17 & 19 & 20 & & 22 & 18 & 21 & 19 & \\
\hline Female & 16 & 10 & 12 & 11 & & 15 & 14 & 9 & 11 & \\
\hline Age (years) & & & & & 0.994 & & & & & 0.723 \\
\hline$<18$ & 21 & 14 & 17 & 16 & & 17 & 17 & 16 & 18 & \\
\hline$\geq 18$ & 19 & 13 & 14 & 15 & & 20 & 15 & 14 & 12 & \\
\hline Location & & & & & 0.565 & & & & & 0.487 \\
\hline Femur & 22 & 11 & 13 & 20 & & 18 & 15 & 19 & 14 & \\
\hline Tibia & 11 & 9 & 10 & 6 & & 8 & 11 & 8 & 9 & \\
\hline Elsewhere & 7 & 7 & 8 & 5 & & 11 & 6 & 3 & 7 & \\
\hline Tumor necrosis rate & & & & & 0.159 & & & & & 0.067 \\
\hline & 31 & 20 & 27 & 29 & & 31 & 22 & 28 & 26 & \\
\hline $\begin{array}{l}<90 \\
\geq 90\end{array}$ & 9 & 7 & 4 & 2 & & 6 & 10 & 2 & 4 & \\
\hline Cortical destruction & & & & & 0.754 & & & & & 0.884 \\
\hline Yes & 33 & 24 & 26 & 28 & & 32 & 27 & 25 & 27 & \\
\hline No & 7 & 3 & 5 & 3 & & 5 & 5 & 5 & 3 & \\
\hline Recurrence & & & & & $0.000 *$ & & & & & $0.000 *$ \\
\hline Yes & 3 & 7 & 19 & 24 & & 3 & 9 & 17 & 24 & \\
\hline No & 37 & 20 & 12 & 7 & & 34 & 23 & 13 & 6 & \\
\hline Metastasis & & & & & 0.514 & & & & & 0.203 \\
\hline Yes & 20 & 15 & 21 & 18 & & 17 & 17 & 21 & 19 & \\
\hline No & 20 & 12 & 10 & 13 & & 20 & 15 & 9 & 11 & \\
\hline Enneking stage & & & & & $0.000 *$ & & & & & $0.000 *$ \\
\hline I & 38 & 25 & 21 & 18 & & 34 & 30 & 23 & 15 & \\
\hline II & 2 & 2 & 10 & 13 & & 3 & 2 & 7 & 15 & \\
\hline
\end{tabular}

$P=0.037)$ and $\mathrm{MCM} 3\left(\chi^{2}=4.939, \mathrm{HR}=1.696\right.$, $P=0.026)$ were independent prognostic factors for TFS (Table 3). The Cox proportional hazards model showed that MCM2 $\left(\chi^{2}=4.568, \mathrm{HR}=1.690, P=0.033\right)$ and MCM3 $\left(\chi^{2}=4.757, \mathrm{HR}=1.718, P=0.029\right)$ were independent prognostic factors for OS (Table 3). The OS and DFS curves for this cohort are presented in Figure 7D-7G. All other factors, including gender, age, tumor location, tumor necrosis rate, cortical destruction, and Enneking stage did not have any significant influence on prognosis. We also performed Kaplan-Meier survival analyses using microarray data (http://www.kmplot. com) obtained from breast and lung cancer patients. We found that MCM2 and MCM3 expression were negatively correlated with patient OS in breast cancer and lung cancer (Supplementary Figure 3). Finally, we detected the expression of DHX9 in osteosarcoma tissues. Representative images of DHX9 expression are shown in Figure 7C. A Spearman correlation analysis revealed a significant correlation between the expression levels of MCM2 and DHX9 $(R=0.195, P=0.027)$, as well as between the levels of MCM3 and DHX9 $(R=0.248$, $P=0.005)$ in osteosarcoma tissues. Taken together, MCM2 and MCM3 were correlated with DHX9 in tumor samples and were associated with poor prognosis in osteosarcoma patients.

\section{DISCUSSION}

Currently, the 5-year survival rate for patients with osteosarcoma is about $70 \%$. However, it has remained almost unchanged over the past three decades. Thus, it is necessary to explore new therapeutic targets. A SWATH ${ }^{\mathrm{TM}}$ experiment, a label-free quantitative proteomic approach, was used to identify osteosarcoma-related nuclear proteins. In this study, 62 upregulated nuclear proteins and 87 downregulated nuclear proteins were identified in osteosarcoma cells compared to osteoblast cells. Then, 23 
nuclear proteins potentially associated with osteosarcoma tumorigenesis were selected for proteomic validation by qRT-PCR, and 12 nuclear proteins were verified by western blotting, many of which were reported closely related to tumorigenesis. Velmurugan et al. reported that ANP32A was highly expressed in oral squamous cell carcinoma and could act as a potential biomarker for the prognosis of oral cancer patients with lymph node metastasis [19]. CTBP1, a co-repressor of tumor suppressor genes, increases breast tumor growth in vitro and in preclinical orthotopic xenograft models [20]. FHL1 has a tumor-suppressive role in tongue squamous cell carcinoma and accordingly may be a useful target for gene therapy [21]. As Rb and IMPDH2 are related to the progression of osteosarcoma $[22,23]$, siRNA transfection and a CCK-8 assay were performed for the functional screening of the other 9 nuclear proteins. The results showed that knockdown of MCM2 or MCM3 inhibited osteosarcoma cell proliferation in $\mathrm{MNNG} / \mathrm{HOS}$ cells, suggesting that they played important roles in the tumorigenesis of osteosarcoma.
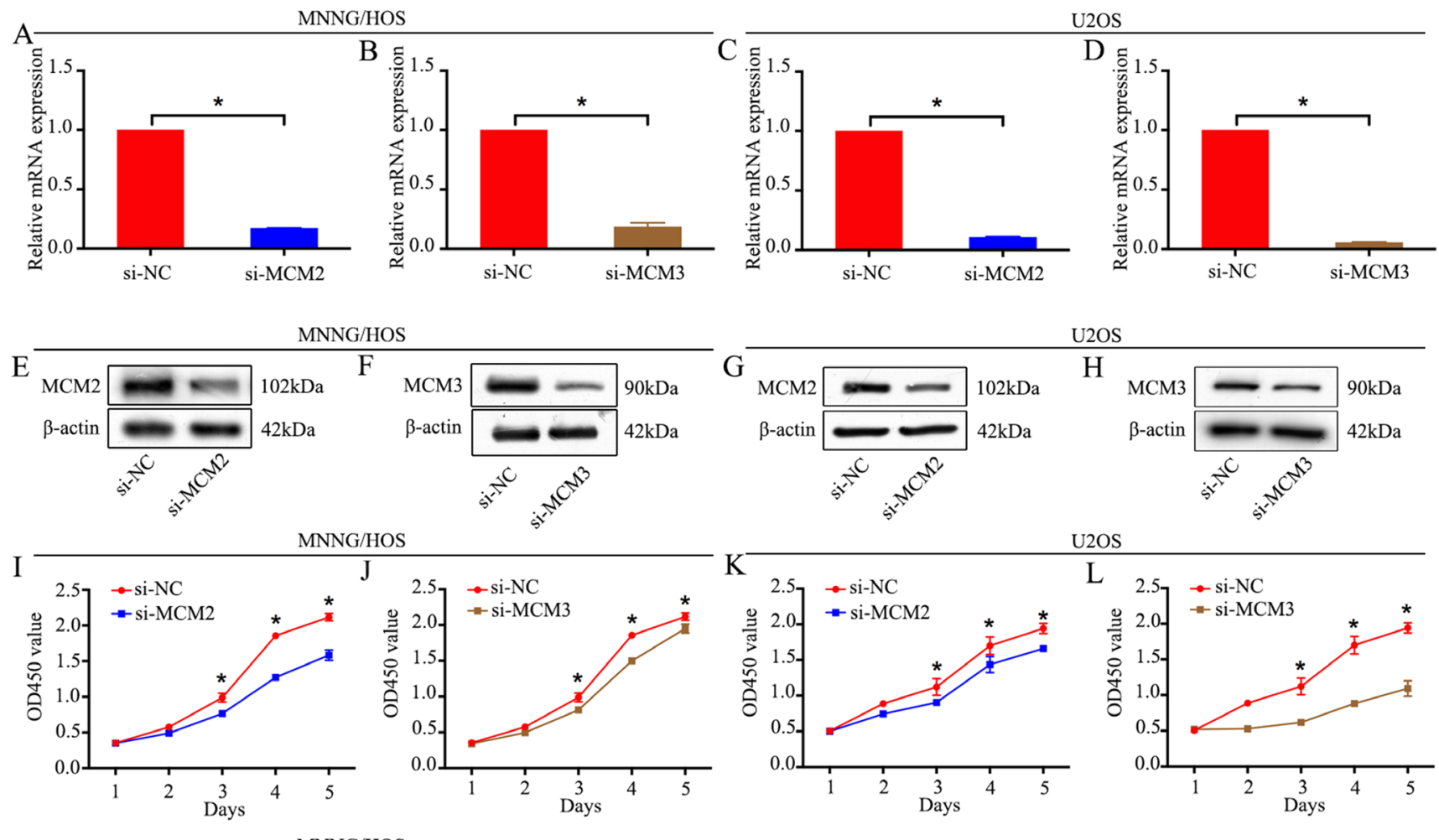

U2OS
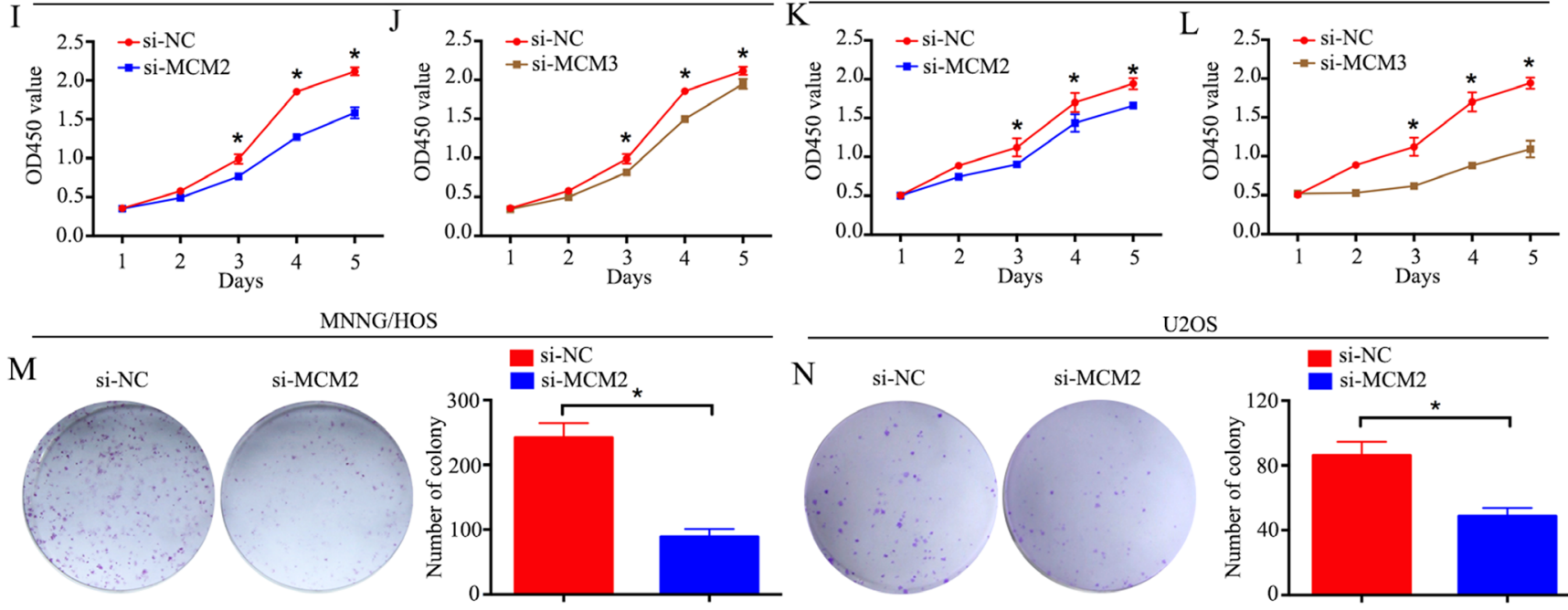

MNNG/HOS
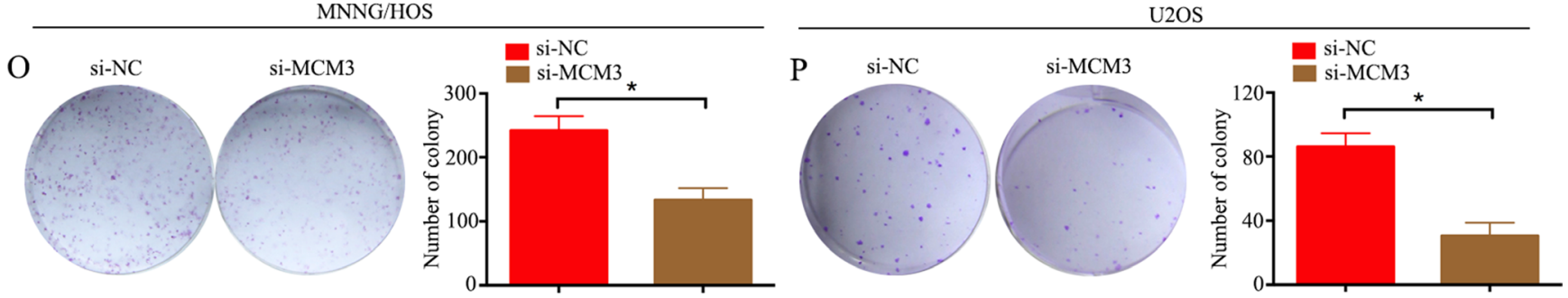

Figure 3:Knockdown of MCM2 or MCM3 inhibits osteosarcoma cell proliferation in vitro. (A-H) The mRNA and protein expression levels were validated after MCM2-specific or MCM3-specific siRNA transfection by qRT-PCR and western blotting in MNNG/ HOS cells and U2OS cells. (I-L) CCK-8 assays were performed after siRNA transfection in MNNG/HOS cells and U2OS cells. (M-P) Colony formation assay for MCM2-silenced or MCM3-silenced osteosarcoma cells and control cells. Data are representative of results from three independent experiments. $* P<0.05$. 
Table 2: Impact of prognostic factors on TFS and OS by univariate analysis in osteosarcoma

\begin{tabular}{|c|c|c|c|c|c|c|c|c|}
\hline \multirow{2}{*}{$\begin{array}{l}\text { Clinicopathologic } \\
\text { parameters }\end{array}$} & \multicolumn{4}{|c|}{ Tumor-free survival } & \multicolumn{4}{|c|}{ Overall survival } \\
\hline & NO. & HR & $95 \% \mathrm{CI}$ & $p$ & NO. & HR & $95 \% \mathrm{CI}$ & $p$ \\
\hline $\begin{array}{l}\text { Gender } \\
\text { Male } \\
\text { Female }\end{array}$ & $\begin{array}{l}80 \\
49\end{array}$ & 0.702 & $0.394-1.251$ & 0.231 & $\begin{array}{l}80 \\
49\end{array}$ & 0.795 & $0.434-1.457$ & 0.457 \\
\hline $\begin{array}{l}\text { Age (years) } \\
<18 \\
\geq 18\end{array}$ & $\begin{array}{l}68 \\
61\end{array}$ & 1.374 & $0.800-2.360$ & 0.250 & $\begin{array}{l}68 \\
61\end{array}$ & 0.861 & $0.487-1.524$ & 0.608 \\
\hline $\begin{array}{l}\text { Location } \\
\text { Femur } \\
\text { Tibia } \\
\text { Elsewhere }\end{array}$ & $\begin{array}{l}66 \\
36 \\
27\end{array}$ & 1.189 & $0.856-1.651$ & 0.302 & $\begin{array}{l}66 \\
36 \\
27\end{array}$ & 1.034 & $0.718-1.491$ & 0.856 \\
\hline $\begin{array}{l}\text { Tumor necrosis } \\
\text { rate }(\%) \\
<90 \\
\geq 90\end{array}$ & $\begin{array}{c}107 \\
22\end{array}$ & 0.670 & $0.302-1.485$ & 0.324 & $\begin{array}{l}107 \\
22\end{array}$ & 0.672 & $0.285-1.586$ & 0.364 \\
\hline $\begin{array}{l}\text { Cortical destruction } \\
\text { Yes } \\
\text { No }\end{array}$ & $\begin{array}{c}111 \\
18\end{array}$ & 0.959 & $0.452-2.037$ & 0.914 & $\begin{array}{c}111 \\
18\end{array}$ & 0.983 & $0.440-2.194$ & 0.966 \\
\hline $\begin{array}{c}\text { MCM2 } \\
0 \\
1 \\
2 \\
3\end{array}$ & $\begin{array}{l}40 \\
27 \\
21 \\
31\end{array}$ & 2.393 & $1.812-3.160$ & $0.000 *$ & $\begin{array}{l}40 \\
27 \\
21 \\
31\end{array}$ & 2.570 & $1.881-3.512$ & $0.000 *$ \\
\hline $\begin{array}{c}\text { MCM3 } \\
0 \\
1 \\
2 \\
3\end{array}$ & $\begin{array}{l}37 \\
32 \\
30 \\
30\end{array}$ & 2.502 & $1.873-3.343$ & $0.000 *$ & $\begin{array}{l}37 \\
32 \\
30 \\
30\end{array}$ & 2.582 & $1.893-3.523$ & $0.000^{*}$ \\
\hline $\begin{array}{l}\text { Enneking stage } \\
\text { I } \\
\text { II }\end{array}$ & $\begin{array}{c}102 \\
27\end{array}$ & 3.361 & $1.927-5.862$ & $0.000^{*}$ & $\begin{array}{c}102 \\
27\end{array}$ & 4.142 & $2.325-7.381$ & $0.000 *$ \\
\hline
\end{tabular}

$* P<0.05$.

Table 3: Variables predictive of survival by COX proportional hazards model in osteosarcoma

\begin{tabular}{cccccc}
\hline & Parametes & Wald $\chi^{2}$ & Risk Ratio & $\mathbf{9 5 \%}$ CI & $\boldsymbol{P}$ \\
\hline \multirow{3}{*}{ TFS } & MCM2 & 4.333 & 1.603 & $1.028-2.499$ & 0.037 \\
& MCM3 & 4.939 & 1.696 & $1.064-2.703$ & 0.026 \\
OS & MCM2 & 4.568 & 1.690 & $1.045-2.734$ & 0.033 \\
& MCM3 & 4.757 & 1.718 & $1.056-2.795$ & 0.029 \\
\hline
\end{tabular}

Several studies have reported a role of MCM family proteins in carcinogenesis. Hua et al. reported that high mRNA expression levels of MCM2 and MCM3 were correlated with a poor outcome and thus might be clinically useful molecular prognostic markers in glioma [24]. Coincidentally, the expression levels of MCM2 and MCM3 are sensitive markers for predicting aggressive and recurrent behaviors of ameloblastoma [25]. The overexpression of MCM2 and MCM3 increased the proliferation and migration of medulloblastoma [26]. A MCM2-targeted strategy might be an effective therapy for the treatment of highly malignant breast cancers [27]. These findings indicate that MCM2 and MCM3 act as oncogenes in tumorigenesis. To date, the role and 
underlying mechanism of MCM2 and MCM3 involved in osteosarcoma remain largely unclear. To assess the effects of MCM2 and MCM3 on osteosarcoma cells, a CCK-8 assay and colony formation assay were performed. In agreement with previous studies, we found that the knockdown of MCM2 and MCM3 resulted in significant cell growth inhibition in vitro. To further clarify the roles of MCM2 and MCM3 in osteosarcoma proliferation, MNNG/HOS cells with the stable knockdown of MCM2 or MCM3 were injected into nude mice. The results showed that MCM2 or MCM3 knockdown could dramatically impede tumor growth in vivo.

Although several studies have reported the role of MCM2 and MCM3 in tumorigenesis, the underlying mechanisms are largely unknown. Costa et al. reported that GINS and Cdc45 activated Mcm2-7 to initiate eukaryotic DNA replication [28]. It has recently been shown that activated Notch downregulated MCM2 and MCM6 to regulate cell proliferation, differentiation, and apoptosis [29]. In the present study, the co-immunoprecipitation technique was used to explore the underlying mechanism by which MCM2 and MCM3 influence osteosarcoma. After mass spectrometry-based protein identification, several proteins attracted our attention, including DHX9, DDX21, RPL4, FBL, RPL7, and RPL7A. We pulled down MCM2 and MCM3 and probed their interactions with other proteins. We presented evidence to support interactions between MCM2/MCM3 and DHX9. No
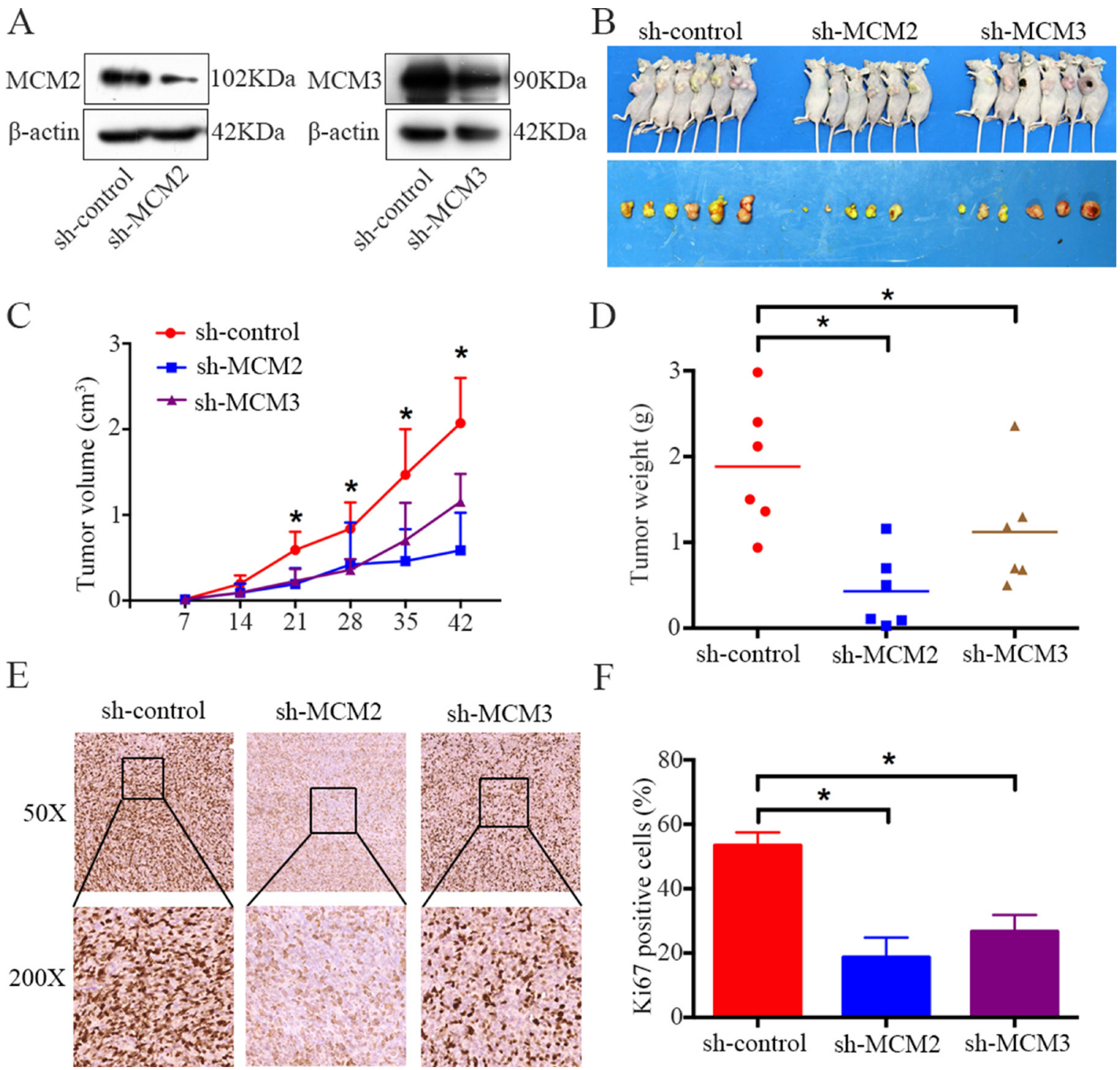

Figure 4: Knockdown of MCM2 or MCM3 inhibits osteosarcoma cell growth in vivo. (A) Representative blots display the protein expression of MCM2 and MCM3 in MNNG/HOS cells stably expressing sh-MCM2 or sh-MCM3. $\beta$-actin was used as an internal control. (B) The upper photograph shows tumor-bearing mice and the lower photograph shows tumors when mice were euthanized. (C) Growth curve drawn by measuring tumor volumes on the indicated days. (D) The diagram shows tumor weights in the sh-control, sh-MCM2, and sh-MCM3 groups. (E, F) Representative images of ki-67 staining in the sh-control, sh-MCM2, and sh-MCM3 groups. Magnification, $\times 50, \times 200 . * P<0.05$. 
interaction was found between either MCM2 or MCM3 and other proteins. Additionally, MCM2 and MCM3 co-localized with DHX9. This study, for the first time, demonstrates the interactions of MCM2/MCM3 with DHX9 in osteosarcoma cells.

DHX9 has been implicated in tumor cell maintenance by participating in transcriptional and translational steps and DNA replication [30-32]. To evaluate if MCM2 and MCM3 functioned via DHX9, a rescue experiment was performed. The overexpression of DHX9 rescued the MCM2 and MCM3 knockdowninduced osteosarcoma growth inhibition, showing that the control of cell proliferation by MCM2 and MCM3 was largely dependent on DHX9. As reported previously, DHX9 interacted with EGFR to activate transcription of EGFR-responsive genes. EGFR was an oncogene overexpressed in several human cancers [33]. In addition, DHX9 was reported to be a NF- $\mathrm{BB}$ binding partner [34], which played an important role in tumorigenesis. Therefore, DHX9 regulates various oncogenes and biological processes in tumors. Overexpression of DHX9

\section{A}
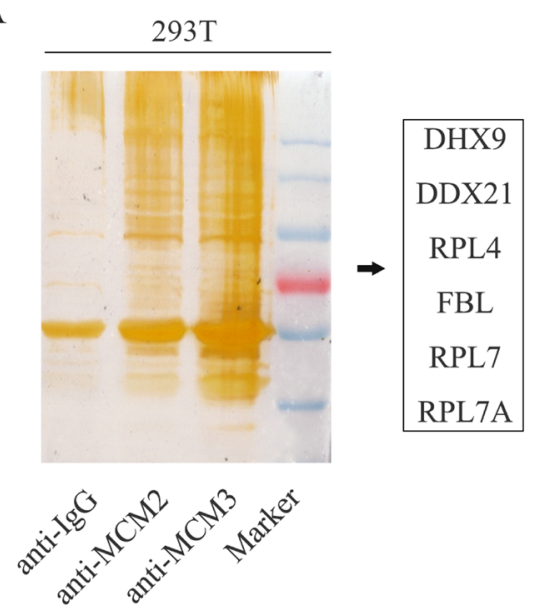

$\mathrm{C}$

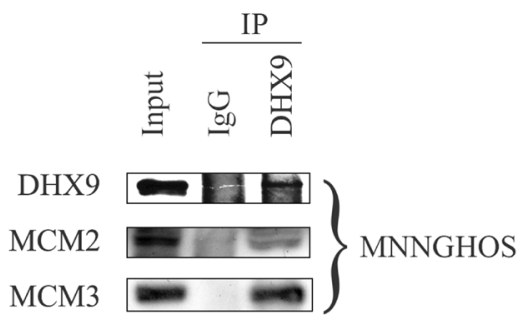

$\mathrm{D}$ rescued the MCM2 and MCM3 knockdown-induced osteosarcoma growth inhibition by regulating numerous biological processes. Additionally, our results showed that knockdown of DHX9 inhibited osteosarcoma cell proliferation. Further validation showed that high MCM2 and MCM3 expression levels in osteosarcoma were associated with a poor prognosis. In addition, positive correlations between both MCM2 and MCM3 and DHX9 were found in osteosarcoma.

Collectively, knockdown of MCM2 or MCM3 dramatically inhibits osteosarcoma cell growth in vitro and in vivo. More importantly, this report provides, for the first time, experimental evidence for interactions of MCM2 and MCM3 with DHX9 in osteosarcoma cells and the importance of these interactions, clarifying the molecular mechanisms of MCM2 or MCM3-mediated tumorigenesis. MCM2 and MCM3 may be sensitive biomarkers to predict prognosis for osteosarcoma patients. Therefore, intervention targeting the MCM2/3-DHX9 axis may be a feasible and effective strategy for the treatment of osteosarcoma.
B
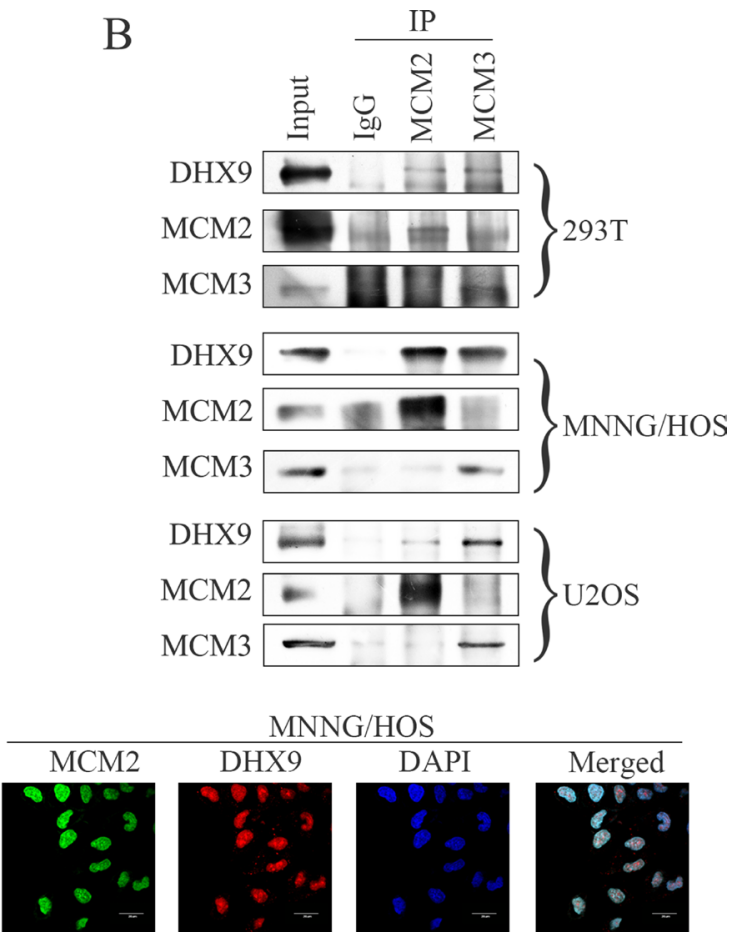

$\mathrm{MCM} 3$

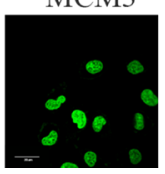

MNNG/HOS

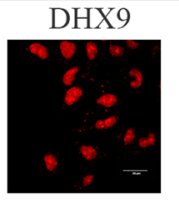

DHX9

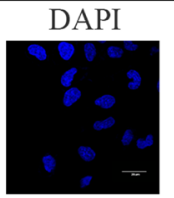

DAPI
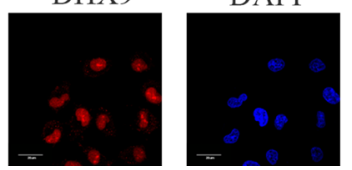

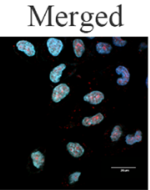

Merged

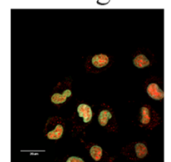

Figure 5: MCM2 and MCM3 interact with DHX9 in osteosarcoma cells. (A) The silver staining for proteins separated by SDS-PAGE after IgG, MCM2, or MCM3 pull-down in 293T cells. (B) Whole-cell lysates were immunoprecipitated with the anti-MCM2 antibody or anti-MCM3 antibody followed by immunoblotting with anti-MCM2, MCM3, and DHX9 antibodies in the 293T cell line and the indicated osteosarcoma cell lines. IgG was used as a negative control. (C) Whole-cell lysates were immunoprecipitated with the antiDHX9 antibody followed by immunoblotting with anti-MCM2, MCM3, and DHX9 antibodies in the MNNG/HOS cell line. IgG was used as a negative control. (D) An immunofluorescence study was performed using anti-MCM2, MCM3, and DHX9 antibodies in the MNNG/ HOS cell line. DAPI was used as a control for nuclear staining. 


\section{MATERIALS AND METHODS}

\section{Cell lines and cell culture}

One human osteoblast cell line (hFOB 1.19), three osteosarcoma cell lines (MNNG/HOS, MG63, and U2OS), and the $293 \mathrm{~T}$ cell line were used. The cells were maintained at $37^{\circ} \mathrm{C}$ in a humidified atmosphere containing $5 \% \mathrm{CO}_{2}$. They were cultured in Dulbecco's modified Eagle's medium (MNNG/HOS, MG63, and 293T) or RPMI-1640 (U2OS) supplemented with 10\% fetal bovine serum (South America Origin; Biowest, Logan, UT, USA), $100 \mathrm{U} / \mathrm{mL}$ penicillin (Sigma-Aldrich, St. Louis, MO, USA) and $100 \mathrm{mg} / \mathrm{mL}$ streptomycin (Sigma-Aldrich). The HFOB 1.19 cell line was cultured according to ATCC protocols.

\section{SWATH ${ }^{\mathrm{TM}}$ measurement}

Nuclear proteins were extracted using NE-PE Nuclear and Cytoplasmic Extraction Reagents (Thermo
Fisher Scientific, Rockford, IL, USA) according to the manufacturer's protocol. Then, $100 \mu \mathrm{g}$ of each sample was reduced with dithiothreitol (DTT) and alkylated with iodoacetic acid (IAA), followed by digestion overnight at $37^{\circ} \mathrm{C}$ with trypsin (Promega, Madison, WI, USA). The peptides were separated in $0.1 \%$ formic acid (FA) and eluted in a linear gradient of $5-30 \%$ solvent B $(98 \%$ $\mathrm{ACN}, 2 \% \mathrm{H} 2 \mathrm{O}$, and $0.1 \% \mathrm{FA}$ ) over $90 \mathrm{~min}$ at a flow rate of $300 \mathrm{~nL} / \mathrm{min}$. Samples were analyzed by mass spectrometry in two phases, data-dependent acquisition (DDA) and SWATH acquisition, on the same samples using the same gradient conditions. The library generation and $\mathrm{SWATH}^{\mathrm{TM}}$ data file processes were described previously [35]. Proteins with at least 2 peptides were used for relative quantitation analyses. With four technical replicates for each sample, the relative quantitation analysis was performed using a $t$-test to determine if group means were significantly different given the standard deviation and the number of samples. Differences in protein levels with a $P$-value of less than 0.05 were considered significant in our experiment.
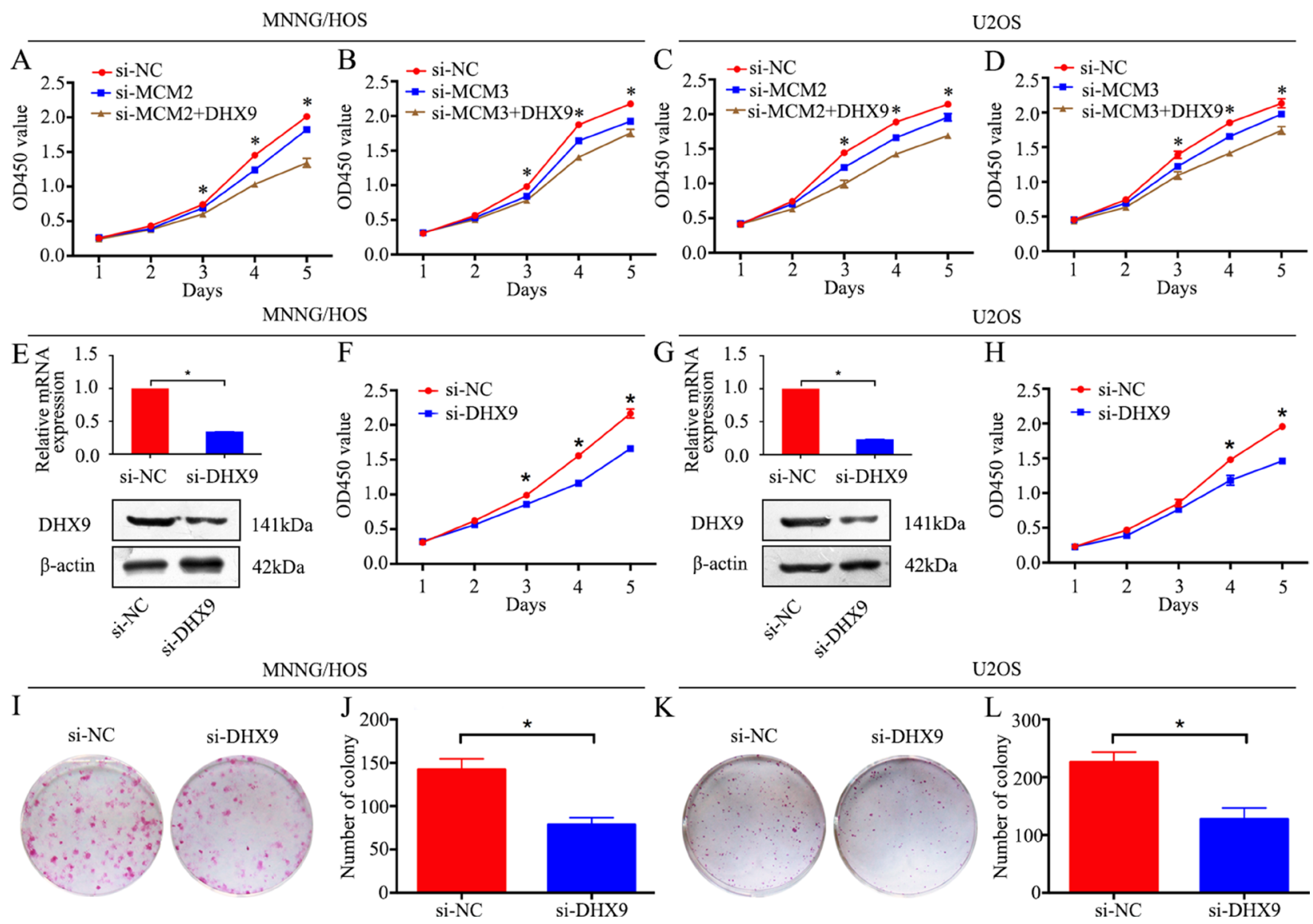

Figure 6: Knockdown of MCM2 or MCM3 inhibits osteosarcoma cell proliferation via DHX9. (A, C) A CCK-8 assay was used to detect tumor cell proliferation after transfection with pcDNA 3.1-DHX9 plus si-MCM2 or si-NC. (B, D) CCK-8 assay was used to detect tumor cell proliferation after transfection with pcDNA 3.1-DHX9 plus si-MCM3 or si-NC. (E, G) The mRNA and protein expression levels were validated after DHX9-specific siRNA transfection by qRT-PCR and western blotting in MNNG/HOS and U2OS cells. $(\mathbf{F}, \mathbf{H})$ A CCK-8 assay was used to detect tumor cell proliferation after transfection with si-DHX9 in MNNG/HOS and U2OS cells. (I, J, K, L) Colony formation assay for DHX9-silenced osteosarcoma cells and control cells. Data are representative of three independent experiments. $* P<0.05$. 


\section{RNA isolation and quantitative real-time PCR assays}

Total RNA was extracted with TRIzol reagent (Invitrogen, Carlsbad, CA, USA) and quantified using the NanoDrop 2000 (Thermo Fisher Scientific, Waltham, MA, USA) according to the manufacturers' protocol. First-strand cDNA was synthesized using the PrimeScript RT Reagent Kit (TaKaRa, Shiga, Japan). RT-PCR was performed with SYBR Green Premix Ex Taq (TaKaRa). All reactions were performed in a $10-\mu \mathrm{L}$ reaction volume in triplicate. The expression levels of genes were measured using the comparative $\mathrm{Ct}$ method. The primer sequences are described in Supplementary Table 1.

\section{Western blot analysis}

Lysates were extracted using a mixture of T-PER Protein Extraction Reagent (Thermo Fisher Scientific), PhosSTOP (Roche, Basel, Switzerland), and Complete Mini (Roche). The protein samples were separated by $6 \%$ or $8 \%$ sodium dodecyl sulfate-polyacrylamide gel electrophoresis and were transferred to nitrocellulose membranes (Millipore, Billerica, MA, USA). After blocking in 5\% non-fat milk, the membranes were incubated with primary antibodies, which are described in Supplementary Table 2. The secondary antibody was
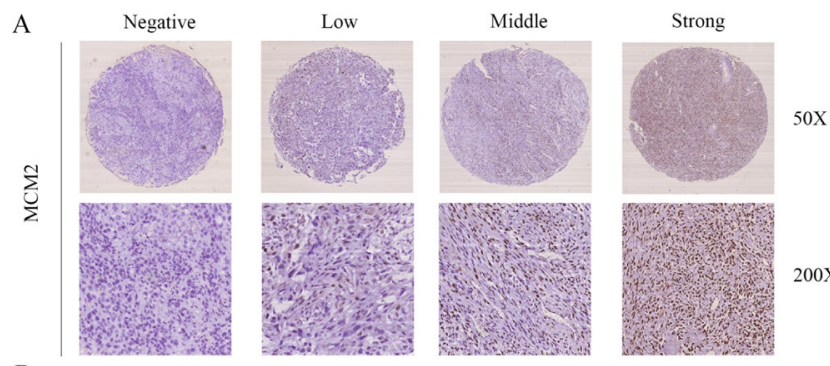

B
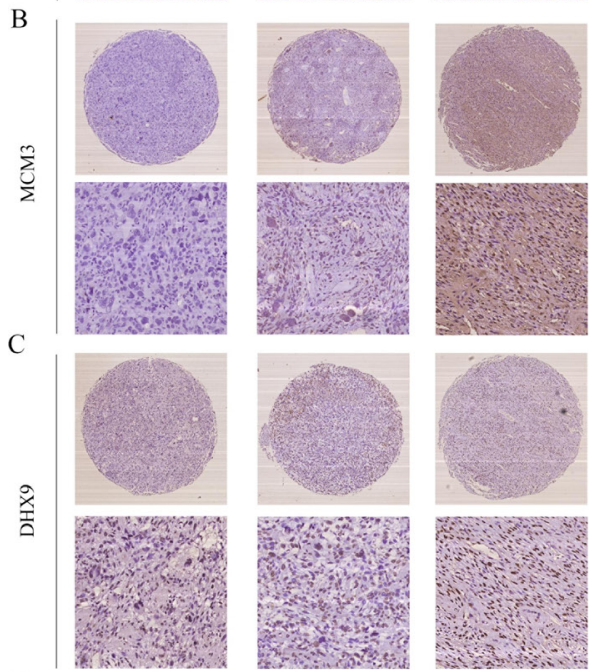

anti-rabbit IgG (Sigma-Aldrich, 1:5000) or anti-mouse IgG (Sigma-Aldrich, 1:5000). Subsequent visualization was performed using SuperSignal West Femto Maximum Sensitivity Substrate (Thermo Fisher Scientific).

\section{Oligonucleotide transfection and stable cell line generation}

Pre-designed siRNA (Ribobio, Guangzhou, China) and plasmids (Public Protein/Plasmid Library, Nanjing, China) were transfected into cells using Lipofectamine 2000 Reagent (Invitrogen) following the manufacturer's protocol. For assays of proliferation, cell cycle, migration, and invasion, and for RNA extraction and western blotting, cells were used $48 \mathrm{~h}$ after transfection. To construct a stable cell line, scramble control, MCM2-specific shRNA, or MCM3-specific shRNA lentiviral particles (Biotend, Shanghai, China) were infected into cells according to the manufacturer's protocol.

\section{Cell proliferation and colony formation assays}

To examine cell proliferation, $48 \mathrm{~h}$ after transfection, 3000 cells were seeded into each well of a 96-well plate and incubated. A $10-\mu \mathrm{L}$ aliquot of CCK-8 (Dojindo, Kumamoto, Japan) was added to triplicate wells and incubated for $2 \mathrm{~h}$. Absorbance at $450 \mathrm{~nm}$ was measured.
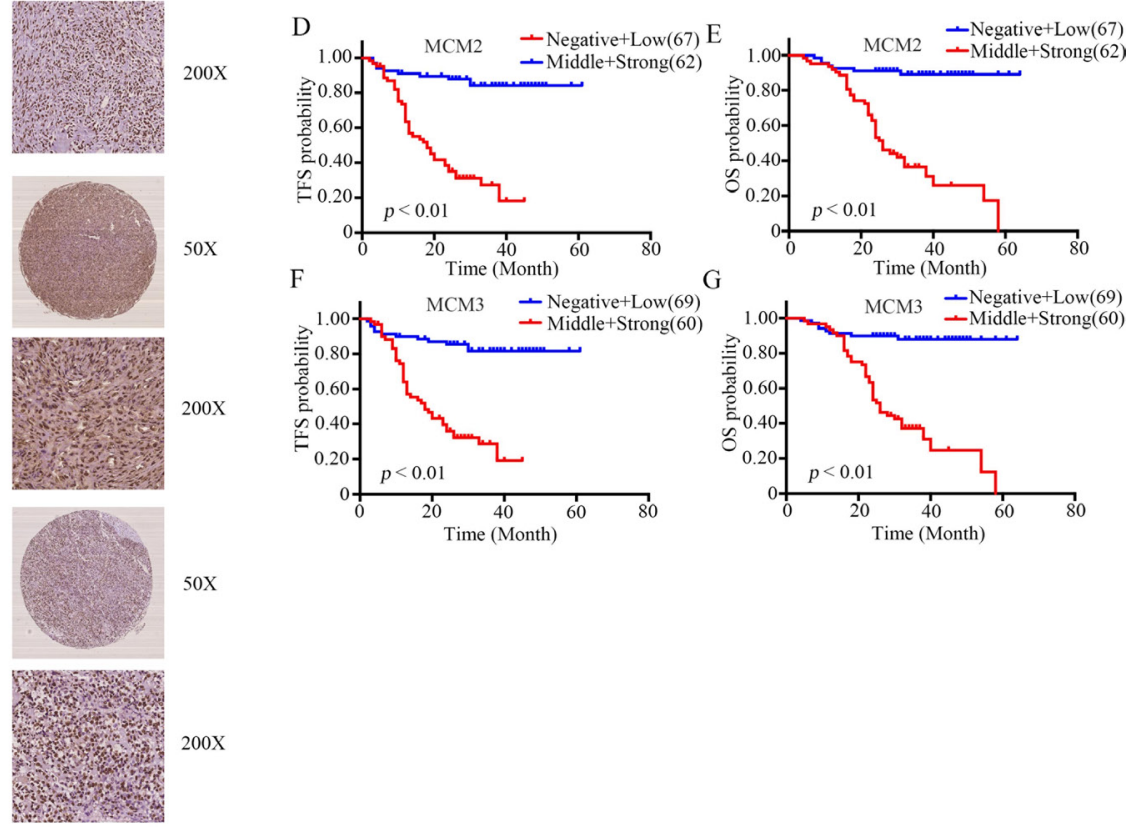

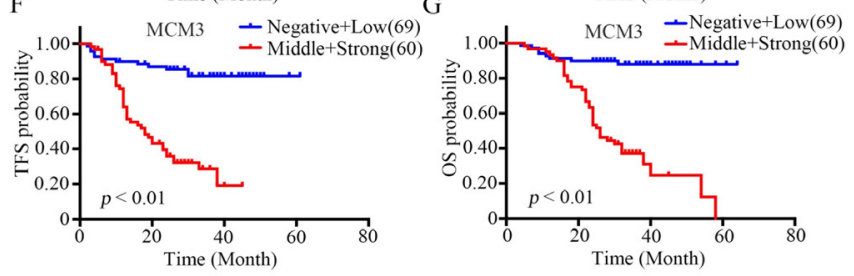

Figure 7: Clinical significance of MCM2 and MCM3 in osteosarcoma patients. (A-C) Representative IHC images of the expression levels (negative: score $=0$, low: score $=1$, middle: score $=2$, and strong: score $=3$ ) of MCM2, MCM3, and DHX9 in osteosarcoma tissues. Original magnification: 50×, 200×. (D-G) The impact of MCM2 and MCM3 on TFS and OS for patients with osteosarcoma. 
Each measurement was performed in triplicate, and the experiments were repeated twice. For the colony formation assay, $48 \mathrm{~h}$ after siRNA transfection, $1 \times 10^{3}$ MNNG/HOS or U2OS cells were seeded in 6-well plates. After 10 days, cells in each well were fixed with $100 \%$ methanol for $30 \mathrm{~min}$ and stained with $0.1 \%$ crystal violet for $30 \mathrm{~min}$. Finally, cell colonies were counted. The assays were independently conducted three times.

\section{Animal experiments}

All animal experiments were approved by the Ethics Committee of the Shanghai Jiao Tong University Affiliated Sixth People's Hospital. For tumor growth assays, MNNG/HOS cells stably expressing sh-control, shMCM2, or sh-MCM3 were injected subcutaneously into the left scapulas of nude mice (6-week-old BALB/c-nu/nu, 6 per group, $2 \times 10^{6}$ cells per mouse). The tumor volume was monitored twice a week and was calculated using the formula: $\mathrm{V}=0.5 \times$ length $\times$ width $^{2}$. After 6 weeks, the mice were euthanized. For the histological analysis, primary tumors were harvested at necropsy and fixed in $10 \%$ formalin. The fixed samples were then embedded in paraffin and three non-sequential serial sections were obtained for each animal.

\section{Co-immunoprecipitation and mass spectrometry protein identification}

Co-immunoprecipitation was performed using 293T, MNNG/HOS, and U2OS cells. Equal amounts of protein $(3000 \mu \mathrm{g})$ were incubated with $\mathrm{IgG}, \mathrm{MCM} 2$, or MCM3 antibodies at $4{ }^{\circ} \mathrm{C}$ overnight and then the mixtures were incubated with protein $\mathrm{A} / \mathrm{G}$ magnetic beads at $4^{\circ} \mathrm{C}$ for $3 \mathrm{~h}$. The beads were washed using phosphatebuffered saline containing 1\% Triton X-100 and eluted using $2 \times$ protein loading buffer at $100^{\circ} \mathrm{C}$ for $10 \mathrm{~min}$. IgG-, MCM2-, or MCM3-bound proteins were resolved by SDS-PAGE and stained using the Silver Staining Kit (Beyotime Biotechnology, Shanghai, China). For the mass spectrometry analysis, MCM2-bound or MCM3-bound proteins were resolved by SDS-PAGE and stained with Coomassie blue R250 (Solarbio, Beijing, China). After destaining, reduction, and trypsin digestion for $12 \mathrm{~h}$, the peptides were extracted using acetonitrile. The peptides were analyzed using a NanoLC System (NanoLC-2D Ultra; Eksigent, Dublin, CA, USA) equipped with a Triple TOF 5600 mass spectrometer (AB SCIEX, Framingham, MA, USA). Protein identification was performed using ProteinPilot4.1 (AB SCIEX). For this study, a strict unused confidence cutoff of $>1.3$ and $\geq 2$ peptides were used for protein identification.

\section{Confocal immunofluorescence}

Confocal immunofluorescence was performed using MNNG cells. Briefly, cells were fixed and incubated with rabbit polyclonal anti-MCM2 or anti-MCM3 antibody and mouse monoclonal anti-DHX 9 antibody at $4{ }^{\circ} \mathrm{C}$ overnight and then incubated with secondary antibodies (Invitrogen) for $1 \mathrm{~h}$. Finally, the cells were incubated with DAPI $(1: 1000)$ for $5 \mathrm{~min}$ and viewed with a Fluoview FV1000 microscope (Olympus, Tokyo, Japan).

\section{Clinical samples and immunohistochemistry (IHC)}

A total of 129 patients diagnosed with osteosarcoma were treated at the Shanghai Sixth People's Hospital. They received primary surgical treatment and preoperative and postoperative neoadjuvant therapy. The median age was 18 years old (range: $5-84$ years). There are 80 males and 49 females. The recurrence rate is $41.09 \%$. There are 66 cases located in the femur, 36 cases located in the tibia and 27 cases located in other bones. The follow-up period ranged from 24 to 64 months, and the median time was 36 months. Ethics approval was obtained from the local hospital ethic committees and written consent was obtained from each patient before sample collection. A standard IHC staining procedure was followed. Paraffin-embedded sections were cut at $4 \mu \mathrm{m}$, dewaxed in xylene, and treated by microwaving at $60^{\circ} \mathrm{C}$ for $20 \mathrm{~min}$ in EDTA buffer $(\mathrm{pH}$ 9.0) for antigen retrieval. Each slide was blocked for endogenous peroxidase activity by incubation in $0.3 \% \mathrm{H}_{2} \mathrm{O}_{2}$ for $10 \mathrm{~min}$, and then incubated at $37^{\circ} \mathrm{C}$ with a $1: 100$ dilution of the polyclonal antibody against MCM2 (Bioworld, Nanjing, China), MCM3 (1:300, Bioworld), DHX9 (1:200, Proteintech), or Ki-67 (1:200, DAKO). Slides were then rinsed three times in PBS, incubated for $30 \mathrm{~min}$ using the EnVision Staining Kit (DAKO, USA), and washed three times in PBS. Color development was performed for 3-10 min in a moist chamber at room temperature using DAB. Slides were counterstained in hematoxylin and dehydrated in graded ethyl alcohol $(70 \%, 90 \%$, and 100\%). The primary antibody was replaced with PBS in sections used as negative controls. Assessment of IHC staining was carried out independently by two expert pathologists. Any discordance was solved by discussion until consensus was reached. The IHC signal intensities were scored as 0 (negative), 1 (low), 2 (middle), or 3 (strong). For ki-67, the percentage of ki-67-positive cells was calculated.

\section{Statistical evaluation}

The data were compiled and analyzed using SPSS version 21.0. Comparisons between different groups were performed using Chi-squared tests. The independent prognostic significance of the parameters was estimated using the Cox proportional hazards model. Survival curves were generated using the Kaplan-Meier method. The correlations between MCM2, MCM3, and DHX9 were analyzed using the Spearman correlation test. The tumorfree survival time was defined as the period from surgery 
to the presence of new local lesions. The overall survival time was defined as the length of time between surgery and death. Results were considered significant at $P<0.05$.

\section{Abbreviations}

MCM2, Minichromosome maintenance protein 2; MCM3, Minichromosome maintenance protein 3; DHX9, DExH-box helicase 9; NUPR1, Nuclear Protein 1; DIA, data-independent acquisition; TFS, tumor-free survival; OS, overall survival; GO, gene ontology; KEGG, Kyoto Encyclopedia of Genes and Genomes.

\section{Authors' contributions}

All authors had full access to the data and participated in the design, analysis and interpretation of the data. All of the authors reviewed the manuscript before submission. All authors read and approved the final manuscript.

\section{ACKNOWLEDGMENTS} experiments.

We thank Professor Ming Yao for help with

\section{CONFLICTS OF INTEREST} interests.

The authors declare that they have no competing

\section{REFERENCES}

1. Huang Z, Li J, Du S, Tang Y, Huang L, Xiao L, Tong P. FKBP14 overexpression contributes to osteosarcoma carcinogenesis and indicates poor survival outcome. Oncotarget. 2016; 7:39872-39884. doi: 10.18632/ oncotarget.9524.

2. Anderson ME. Update on Survival in Osteosarcoma. Orthop Clin North Am. 2016; 47:283-92. doi: 10.1016/j. ocl.2015.08.022.

3. Gutowski CJ, Basu-Mallick A, Abraham JA. Management of Bone Sarcoma. Surg Clin North Am. 2016; 96:1077-106. doi: 10.1016/j.suc.2016.06.002.

4. Shahbazi J, Scarlett CJ, Norris MD, Liu B, Haber M, Tee AE, Carrier A, Biankin AV, London WB, Marshall GM, Lock RB, Liu T. Histone deacetylase 2 and N-Myc reduce p53 protein phosphorylation at serine 46 by repressing gene transcription of tumor protein 53-induced nuclear protein 1. Oncotarget. 2014; 5:4257-68. doi: 10.18632/ oncotarget.1991.

5. Gustafsson Sheppard N, Jarl L, Mahadessian D, Strittmatter L, Schmidt A, Madhusudan N, Tegnér J, Lundberg EK, Asplund A, Jain M, Nilsson R. The folatecoupled enzyme MTHFD2 is a nuclear protein and promotes cell proliferation. Sci Rep. 2015; 5:15029. doi: 10.1038/srep15029.

6. Pedrola N, Devis L, Llauradó M, Campoy I, MartinezGarcia E, Garcia M, Muinelo-Romay L, AlonsoAlconada L, Abal M, Alameda F, Mancebo G, Carreras R, Castellví J, et al. Nidogen 1 and Nuclear Protein 1: novel targets of ETV5 transcription factor involved in endometrial cancer invasion. Clin Exp Metastasis. 2015; 32:467-78. doi: 10.1007/s10585-015-9720-7.

7. Indovina P, Marcelli E, Pentimalli F, Tanganelli P, Tarro G, Giordano A. Mass spectrometry-based proteomics: the road to lung cancer biomarker discovery. Mass Spectrom Rev. 2013; 32:129-42. doi: 10.1002/mas.21355.

8. Carretero J, Shimamura T, Rikova K, Jackson AL, Wilkerson MD, Borgman CL, Buttarazzi MS, Sanofsky BA, McNamara KL, Brandstetter KA, Walton ZE, Gu TL, Silva JC, et al. Integrative genomic and proteomic analyses identify targets for Lkb1-deficient metastatic lung tumors. Cancer Cell. 2010; 17:547-59. doi: 10.1016/j. ccr.2010.04.026.

9. Ghosh D, Li Z, Tan XF, Lim TK, Mao Y, Lin Q. iTRAQ based quantitative proteomics approach validated the role of calcyclin binding protein (CacyBP) in promoting colorectal cancer metastasis. Mol Cell Proteomics. 2013; 12:1865-80. doi: 10.1074/mcp.M112.023085.

10. Olsson N, Carlsson P, James P, Hansson K, Waldemarson S, Malmström P, Fernö M, Ryden L, Wingren C, Borrebaeck CA. Grading breast cancer tissues using molecular portraits. Mol Cell Proteomics. 2013; 12:3612-23. doi: 10.1074/mcp. M113.030379.

11. Hao J, Li W, Dan J, Ye X, Wang F, Zeng X, Wang L, Wang H, Cheng Y, Liu L, Shui W. Reprogramming- and pluripotencyassociated membrane proteins in mouse stem cells revealed by label-free quantitative proteomics. J Proteomics. 2013; 86:70-84. doi: 10.1016/j.jprot.2013.04.018.

12. Wu JX, Song X, Pascovici D, Zaw T, Care N, Krisp C, Molloy MP. SWATH Mass Spectrometry Performance Using Extended Peptide MS/MS Assay Libraries. Mol Cell Proteomics. 2016; 15:2501-14. doi: 10.1074/mcp. M115.055558.

13. Simbürger JM, Dettmer K, Oefner PJ, Reinders J. Optimizing the SWATH-MS-workflow for label-free proteomics. J Proteomics. 2016; 145:137-40. doi: 10.1016/j.jprot.2016.04.021.

14. Mehdi MZ, Nagi AH, Naseem N. MCM-2 and Ki67 as proliferation markers in renal cell carcinoma: A quantitative and semi-quantitative analysis. Int Braz $\mathrm{J}$ Urol. 2016; 42:1121-1128. doi: 10.1590/S1677-5538. IBJU.2015.0388.

15. Ishibashi $\mathrm{Y}$, Kinugasa $\mathrm{T}$, Akagi $\mathrm{Y}$, Ohchi T, Gotanda $\mathrm{Y}$, Tanaka N, Fujino S, Yuge K, Kibe S, Yoshida N, Mizobe T, Oka Y, Yoshida T, et al. Minichromosome maintenance protein 7 is a risk factor for recurrence in patients with Dukes C colorectal cancer. Anticancer Res. 2014; 34:4569-75. 
16. Lin HC, Zhang FL, Geng Q, Yu T, Cui YQ, Liu XH, Li J, Yan MX, Liu L, He XH, Li JJ, Yao M. Quantitative proteomic analysis identifies CPNE3 as a novel metastasispromoting gene in NSCLC. J Proteome Res. 2013; 12:3423-33. doi: 10.1021/pr400273z.

17. Chen Z, Wang Z, Guo W, Zhang Z, Zhao F, Zhao Y, Jia D, Ding J, Wang H, Yao M, He X. TRIM35 Interacts with pyruvate kinase isoform M2 to suppress the Warburg effect and tumorigenicity in hepatocellular carcinoma. Oncogene. 2015;34:3946-56. doi: 10.1038/onc.2014.325.

18. Mardanpour K, Rahbar M, Mardanpour S. Coexistence of HER2, Ki67, and p53 in Osteosarcoma: A Strong Prognostic Factor. N Am J Med Sci. 2016;8:210-4. doi: 10.4103/19472714.183013.

19. Velmurugan BK, Yeh KT, Lee $\mathrm{CH}$, Lin SH, Chin MC, Chiang SL, Wang ZH, Hua CH, Tsai MH, Chang JG, Ko YC. Acidic leucine-rich nuclear phosphoprotein32A (ANP32A) association with lymph node metastasis predicts poor survival in oral squamous cell carcinoma patients. Oncotarget. 2016; 7:10879-90. doi: 10.18632/ oncotarget.7681.

20. De Luca P, Dalton GN, Scalise GD, Moiola CP, Porretti J, Massillo C, Kordon E, Gardner K, Zalazar F, Flumian C, Todaro L, Vazquez ES, Meiss R, et al. CtBP1 associates metabolic syndrome and breast carcinogenesis targeting multiple miRNAs. Oncotarget. 2016; 7:18798-811. doi: 10.18632/oncotarget.7711.

21. Ren W, Lian P, Cheng L, Du P, Guan X, Wang H, Ding L, Gao Z, Huang X, Xiao F, Wang L, Bi X, Ye Q, et al. FHL1 inhibits the growth of tongue squamous cell carcinoma cells via G1/S cell cycle arrest. Mol Med Rep. 2015; 12:3958-64. doi: 10.3892/mmr.2015.3844.

22. Wang JY, Wu PQ, Chen PC, Lee CW, Chen WM, Hung SC. Generation of Osteosarcomas From a Combination of $\mathrm{Rb}$ Silencing and c-Myc Overexpression in Human Mesenchymal Stem Cells. Stem Cells Transl Med. 2016. doi: 10.5966/sctm.2015-0226.

23. Li HX, Meng QP, Liu W, Li YG, Zhang HM, Bao FC, Song LL, Li HJ. IMPDH2 mediate radioresistance and chemoresistance in osteosarcoma cells. Eur Rev Med Pharmacol Sci. 2014; 18:3038-44.

24. Hua C, Zhao G, Li Y, Bie L. Minichromo some Maintenance (MCM) Family as potential diagnostic and prognostic tumor markers for human gliomas. BMC Cancer. 2014;14:526. doi: 10.1186/1471-2407-14-526.

25. Carreón-Burciaga RG, González-González R, MolinaFrechero N, Bologna-Molina R. Immunoexpression of Ki-67, MCM2, and MCM3 in Ameloblastoma and Ameloblastic Carcinoma and Their Correlations with Clinical and Histopathological Patterns. Dis Markers. 2015;2015:683087. doi: 10.1155/2015/683087.
26. Lau KM, Chan QK, Pang JC, Li KK, Yeung WW, Chung NY, Lui PC, Tam YS, Li HM, Zhou L, Wang Y, Mao Y, $\mathrm{Ng}$ HK. Minichromosome maintenance proteins 2, 3 and 7 in medulloblastoma: overexpression and involvement in regulation of cell migration and invasion. Oncogene. 2010; 29:5475-89. doi: 10.1038/onc.2010.287.

27. Abe S, Yamamoto K, Kurata M, Abe-Suzuki S, Horii R, Akiyama F, Kitagawa M. Targeting MCM2 function as a novel strategy for the treatment of highly malignant breast tumors. Oncotarget. 2015; 6:34892-909. doi: 10.18632/ oncotarget.5408.

28. Costa A, Ilves I, Tamberg N, Petojevic T, Nogales E, Botchan MR, Berger JM. The structural basis for MCM27 helicase activation by GINS and Cdc45. Nat Struct Mol Biol. 2011; 18:471-7. doi: 10.1038/nsmb.2004.

29. Noseda M, Karsan A. Notch and minichromosome maintenance (MCM) proteins: integration of two ancestral pathways in cell cycle control. Cell Cycle. 2006; 5:2704-9. doi: 10.4161/cc.5.23.3515.

30. Lee T, Paquet M, Larsson O, Pelletier J. Tumor cell survival dependence on the DHX9 DExH-box helicase. Oncogene. 2016; 35:5093-105. doi: 10.1038/onc.2016.52.

31. Fidaleo M, Svetoni F, Volpe E, Miñana B, Caporossi D, Paronetto MP. Genotoxic stress inhibits Ewing sarcoma cell growth by modulating alternative pre-mRNA processing of the RNA helicase DHX9. Oncotarget. 2015; 6:31740-57. doi: 10.18632/oncotarget.5033.

32. Chen ZX, Wallis K, Fell SM, Sobrado VR, Hemmer MC, Ramsköld D, Hellman U, Sandberg R, Kenchappa RS, Martinson T, Johnsen JI, Kogner P, Schlisio S. RNA helicase $\mathrm{A}$ is a downstream mediator of KIF1B $\beta$ tumorsuppressor function in neuroblastoma. Cancer Discov. 2014; 4:434-51. doi: 10.1158/2159-8290.CD-13-0362.

33. Lee T, Pelletier J. The biology of DHX9 and its potential as a therapeutic target. Oncotarget. 2016; 7:42716-42739. doi: 10.18632/oncotarget.8446.

34. Zucchini C, Rocchi A, Manara MC, De Sanctis P, Capanni C, Bianchini M, Carinci P, Scotlandi K, Valvassori L. Apoptotic genes as potential markers of metastatic phenotype in human osteosarcoma cell lines. Int J Oncol. $2008 ; 32: 17-31$.

35. Zhang F, Lin H, Gu A, Li J, Liu L, Yu T, Cui Y, Deng W, Yan M, Li J, Yao M. SWATHTM- and iTRAQ-based quantitative proteomic analyses reveal an overexpression and biological relevance of CD109 in advanced NSCLC. J Proteomics. 2014; 102:125-36. doi: 10.1016/j.jprot.2014.03.007. 